\title{
THE MECHANISMS OF SELECTIVITY AND ACTION OF PROTEIN SYNTHESIS INHIBITORS
}

\author{
D. VAZQUEZ \\ Instituto de Biologia Celular, Velazquez 144, Madrid-6, Spain
}

\begin{abstract}
Systems for protein biosynthesis can be broadly classified, according to their mechanism and the sclective action of drugs on thcir reactions, in two groups: the prokaryotic type (including bacterial, mitochondrial and chloroplasts systems) and the eukaryotic type (including cytoplasmic systems from mammals, higher plants, green algae, yeast, fungi and protozoa).

Inhibitors of protein synthesis are classificd according to their specificity into those acting on (a) prokaryotic systems, (b) cukaryotic systems and (c) both prokaryotic and eukaryotic systems. Within this specificity they are further classified into those affecting (a) the small ribosome subunit, (b) the large ribosome subunit and (c) the supernatant factors. Taking into account the reactions in which they interfere, inhibitors of protein synthesis arc classified into those inhibiting (a) the initiation phase, (b) the elongation phase and (c) the termination phase of protein synthesis.
\end{abstract}

\section{THE MECHANISM OF PROTEIN SYNTHESIS}

Translation of mRNA in protein takes place at the ribosome level. As shown in Figure 1 the ribosome has two subunits which are separated after synthesis of the polypeptide chain is finished. We can distinguish along the ribosome, and including the subunits, two sites: the donor-or P-site and the acceptor-or A-site. The peptidyl transferase centre, which catalyzes peptide bond formation, is integrated into the structure of the larger ribosome subunit; part of this centre is on the P-site whereas another part is on the A-site. The overall reactions taking place in the biosynthesis of proteins by $E$. coli ribosomes according to the two entry sites translocation model is shown in Figure $2^{1}$. For the purpose of understanding the whole process, it can be divided in three phases: (a) initiation, (b) elongation and (c) termination (Figure 2).

The initiation phase starts with the initiator formyl-methionyl-tRNA coded by the initiator triplet AUG at the $5^{\prime}$ end of the mRNA and the order of nucleotide triplets in the $3^{\prime}$ direction determines the order in which subsequent aminoacyl-tRNA bind to the mRNA-ribosome complex. The anticodon region of tRNA is recognized and its interaction with mRNA 


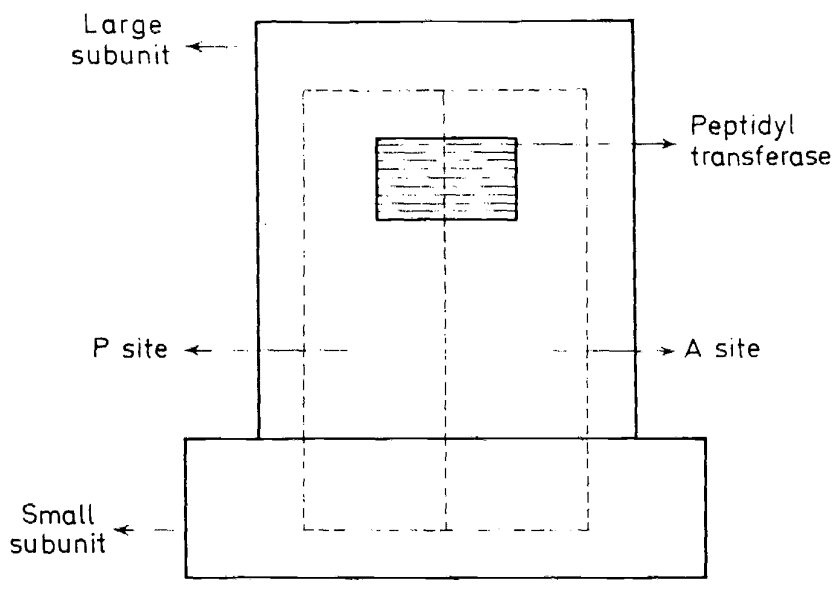

Figure 1. Ribosome structure.

specifically stabilized by the $30 \mathrm{~S}$ subunit in a reaction requiring the initiation factors IF 1, IF 2, IF 3 and GTP (Figures $2 a$ and $2 b$ ). In a further reaction a $50 \mathrm{~S}$ ribosome subunit joins the mRNA-30S-f-Met-tRNA complex to complete the initiation complex with f-Met-tRNA bound to the donor-or P-site (Figure 2c). One GTP molecule is cleaved into GDP and $\mathrm{Pi}$ in the initiation phase; after the joining of the 50S subunit (Figure 2c). It is known that besides the codon-anticodon interaction at the level of the $30 \mathrm{~S}$ ribosomal subunit, some portions of the tRNA, in particular the f-Met-bearing moiety, interact with the 50S subunit. The specificity for the initiating role of f-Met-tRNA and its binding to the $\mathrm{P}$-site is due to the $\alpha-\mathrm{NH}_{2}$ group of the methionine being blocked by formylation and to the unique structure of the tRNA $\mathrm{F}_{\mathrm{F}}$.

In the elongation phase the aminoacyl-tRNA determined by the nucleotide triplet adjacent to the initiation codon is bound to the ribosomal acceptoror A-site (Figure $2 d_{1}$ ). Prior formation of the complex [elongation factor (EF) Tu-AA $\left.-\mathrm{ARNA}_{1}-\mathrm{GTP}\right]$ is required which in the binding reaction splits and EF Tu-GDP + Pi is separated. Once the f-Met-tRNA is in the P-site and $\mathrm{AA}_{1}-\mathrm{tRNA} \mathrm{A}_{1}$ is bound to the A-site, peptide bond formation takes place catalyzed by the peptidyl transferase which is an integral part of the $50 \mathrm{~S}$ ribosome subunit (Figure $2 e_{1}$ ). Peptide bond formation takes place by transfer of the f-Met moiety in such a way that the -.. COOH group of methionine is linked to the $\alpha-\mathrm{NH}_{2}$ group of the amino acid $\mathrm{AA}_{1}-\mathrm{tRNA}$ bound to the $A$-site. The stripped tRNA $A_{F}$ is then released from the P-site and the f-Met- $\mathrm{AA}_{1}$-tRNA $\mathrm{RN}_{1}$ moved to the P-site in a complex step known as translocation (Figure $2 f_{1}$ ). The elongation factor EFG and GTP are required in this reaction and one molecule of GTP is cleaved to GDP + Pi. Movement of the mRNA in the direction $5^{\prime} \rightarrow 3^{\prime}$ is coupled to movement of the f-Met- $\mathrm{AA}_{1}-\mathrm{tRNA} \mathrm{R}_{1}$ from the A-to the P-site. Translocation results in the positioning of the next codon into site $A$ which in turn allows entry and 
specification of $\mathrm{AA}_{2}-\mathrm{tTNA} \mathrm{T}_{2}$ (Figure $2 d_{2}$ ) in a reaction similar to that of $\mathrm{AA}_{1}$-tRNA $\mathrm{A}_{1}$ binding as described above. The ribosomal peptidyl transferase centre will then transfer the f-Met-AA $-\mathrm{tRNA_{1 }}$ to the A-site thus forming f-Met-AA $-A_{1}-A_{2}-t R N A_{2}$. By repetition of the steps involved in the elongation cycle (aminoacyl-tRNA binding, peptide bond formation, translocation) the growth of the polypeptidyl-tRNA chain takes place with the polypeptide bound to the ribosome through the tRNA carrying the last amino acid incorporated into the chain.

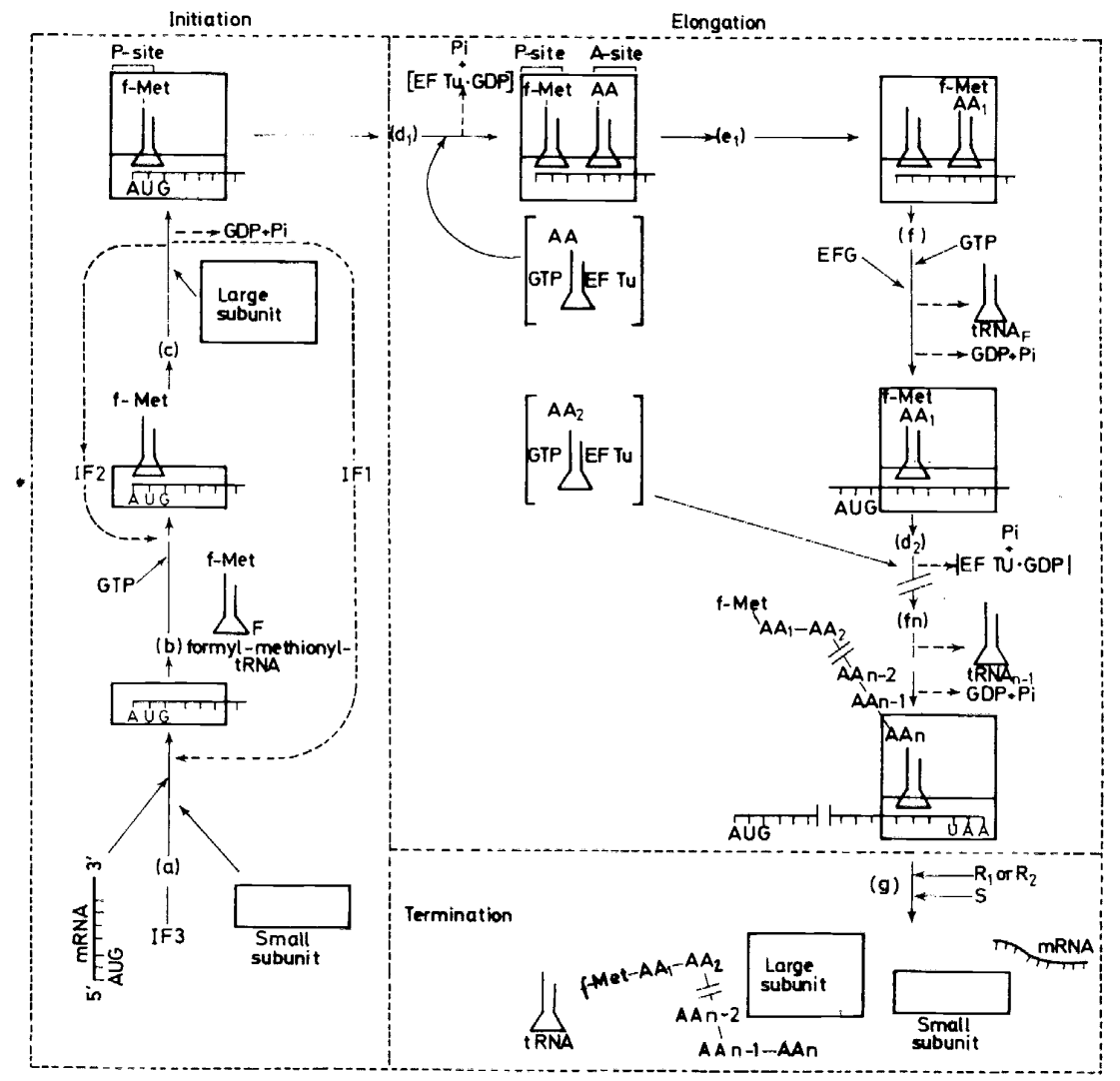

Figure 2. Protein synthesis by E. coli ribosomes.

For the termination phase a chain-terminating codon (nonsense codon) (either UAA or UAG or UGA) is recognized and the bond between the peptidyl and tRNA moieties of peptidyl-tRNA is cleaved in a reaction requiring the release factors (either $R_{1}$ or $R_{2}$ ) and the supernatant factor $S$ (Figure 2g).

Basically the same mechanism for protein synthesis as in E. coli is found in organisms other than bacteria. However there are at least two broad 
classes of systems for protein synthesis; one of them is the prokaryotic type (including bacteria, blue-green algae, mitochondria, chloroplasts and possibly nuclei) and the other one is the eukaryotic type (including systems from the cytoplasm of yeast, fungi, green algae, protozoa, higher plants and mammalian cells). Since bacterial ribosomes have a sedimentation coefficient of 70 svedbergs, ribosomes of the prokaryotic systems have been known frequently altogether as ' $70 \mathrm{~S}$ type ribosomes' although it is now known that mitochondrial ribosomes are certainly smaller. Eukaryotic ribosomes are generally known as ' $80 \mathrm{~S}$ type ribosomes' as their sedimentation coefficient is close to that figure. Bacterial ribosome subunits are $50 \mathrm{~S}$ and $30 \mathrm{~S}$ whereas those of eukaryotic ribosomes are $60 \mathrm{~S}$ and $40 \mathrm{~S}$. The ribosomal subunits in eukaryotic type ribosomes perform similar functions to their prokaryotic counterparts, namely peptide bond formation on the larger subunit and codon-anticodon recognition in the smaller one (see Figure 1). However, functional differences between the prokaryotic and eukaryotic types of systems for protein synthesis are shown not only in the ribosomes but also in the initiator and in the different supernatant factors (initiation, elongation and release factors), since there is ample evidence that ribosomes and supernatant factors can be crossed between widely different systems belonging to the same type but not between systems of different types. The elongation factors EF-1 and EF-2 have been shown to have in eukaryotic systems a role rather similar to the bacterial factors EF-T and EF-G respectively; the release factor $R$ has been shown to be required in eukaryotic systems and initiation factors have been isolated from eukaryotic cells but are not so well resolved yet as in bacterial systems. Furthermore some important differences have been shown within the prokaryotic type ribosomes since the 5S ribosomal RNA is known to be present in bacterial and chloroplast ribosomes but has never been found in mitochondrial ribosomes. Perhaps due to this difference no reconstitution of active ribosomes has been observed when the small subunit of mitochondrial ribosomes and the large subunit from bacterial ribosomes or vice-versa are mixed whereas there is reconstitution of active ribosomes when hybrid mixtures of chloroplasts and bacterial ribosome subunits are mixed. However for the purpose of the antibiotic action, we can consider, broadly speaking, all prokaryotic systems as a unit.

\section{SELECTIVITY OF PROTEIN SYNTHESIS INHIBITORS}

Most of the antibiotics known to block protein synthesis act at the ribosome level. Since there are at least two types of systems for protein synthesis, their inhibitors can be classified according to their specificity, into those affecting systems of (a) the prokaryotic type, (b) the eukaryotic type and (c) both the prokaryotic and the eukaryotic types (Table 1$)^{2-10}$. Some of these inhibitors bind or affect directly either of the elongation factors (e.g. diphtheria toxin, fusidic acid and emetine) but most of them interact directly with the ribosome. There are still discrepancies regarding some of the results presented in Table 1. An important one concerns diphtheria toxin which is indicated in this Table as a specific inhibitor of elongation factor 


\section{PROTEIN SYNTHESIS INHIBITORS}

Table 1. Inhibitors of protein synthesis

Althiomycin

Berninamycin

Chloramphenicol group:

Chloramphenicol

D-AMP-3

D-Thiomycetin

D-Win-5094

Kasugamycin

Lincomycin group:

Celesticetin

Clindamycin

Lincomycin (see Refs. 18, 19)

Macrolides group:

Angolamycin

Carbomycin

Erythromycin (see Refs. 18, 19)

Forocidin

Lancamycin

Leucomycin

Methymycin

Neospiramycin

Oleandomycin

Spiramycin

Tylosin
Acting on prokaryotic systems

\author{
Micrococcin \\ Multhiomycin \\ Siomycin group: \\ Siomycin \\ Sporangiomycin \\ Thiopeptin \\ Thiostrepton (Bryamycin) \\ Spectinomycin \\ Streptogramin A group: \\ Ostreogrycin G \\ Streptogramin A
}

Streptogramin B group:

Staphylomycin S

Streptogramin B

Viridogrisein

Streptomycin group:

Gentamycin

Hygromycin B

Kanamycin (see Refs. 18, 19)

Neomycin (see Refs. 18, 19)

Paromomycin (see Refs. 18, 19)

Streptomycin

Viomycin

\section{Actinobolin}

Amicetin

Aurintricarboxylic acid

Blasticidin $S$

Bottromycin $\mathrm{A}_{2}$

Chartreusin

Edeine $\mathbf{A}_{1}$

Fusidic acid (see Refs. 16, 17)

Gougerotin
Acting on prokaryotic and eukaryotic systems

Nucleocidin

Pactamycin

Poly(dextran sulphate)

Poly(vinyl sulphate)

Puromycin

Sparsomycin

Tetracycline group:

Chlortetracycline

Doxycycline

Oxytetracycline

Tetracycline
Anisomycin

Diphtheria toxin (see Refs. 10-15)

Emetine

Enomycin

Glutarimide group:

Actiphenol

Cycloheximide

Streptimidone

Streptovitacin A
Acting on eukaryotic systems

Pederine

Phenomycin

Tenuazonic acid

Tylophora alkaloids :

Cryptopleurine

Tylocrebrine

Tylophorine

Trichodermın

Tenuazonic acid

EF-2 of eukaryotic systems as accepted by most workers ${ }^{11-14}$ : however, one group maintains that diphtheria toxin also binds specifically to the small subunit of bacterial ribosomes blocking the subsequent binding of 
aminoacyl-tRNA ${ }^{15-17}$. Also in a few cases it appears that antibiotic sensitivity of systems of a given type differs within the different specific systems. For instance although EF-G from Neurospora crassa has been found to be interchangeable with bacterial $\mathrm{EF}-\mathrm{G}^{18}$, this factor from bacteria is sensitive to fusidic acid whereas the EF-G from Neurospora is not affected by this antibiotic ${ }^{19}$. Another interesting example is that of the antibiotics erythromycin, lincomycin, neomycin, kanamycin and streptomycin which have been shown to block protein synthesis by bacterial and yeast ribosomes but have been reported not to be active on ribosomes from mammalian mitochondria ${ }^{20,21}$. Two of the tylophora alkaloids (cryptopleurine and tylophorine) although included in Table 1 as specific inhibitors of eukaryotic systems have also been reported to have a certain effect on yeast mitochondrial ribosomes ${ }^{22}$. Finally, not yet well-resolved cell-free systems from some mammalian structures have been reported to be sensitive to chloramphenicol and resistant to cycloheximide ${ }^{23}$ contrarily to what might be predicted from the selectivity indicated in Table 1. However most of these apparently anomalous or exceptional results have only been reported by single groups of workers ${ }^{15-23}$.

\section{RIBOSOME SUBUNITS AS SPECIFIC TARGETS OF ANTIBIOTIC ACTION}

The available methods to determine on which ribosome subunit a given antibiotic acts can be summarized as follows: (a) binding of radioactive antibiotics or competition with this binding; (b) reconstitution of hybrid ribosomes from ribosome subunits derived from antibiotic-sensitive and resistant cells, followed by studies on sensitivity of these reconstituted ribosomes to the required antibiotic; (c) studies on protein-synthesizing activity of ribosomes reconstituted from ribosome subunits pretreated independently with the required antibiotic followed by subsequent removal of the unbound inhibitor (by gel filtration, centrifugation, filtration or any other possible method) before the reconstitution experiments; (d) effects of antibiotics on a function specifically associated with a ribosome subunit which can be studied in the absence of the other subunit; and (e) it can be assumed that a number of antibiotics known to act on both bacterial and eukaryotic protein synthesis do so by blocking homologous steps in one or another case. Concerning point (d) indicated above we know at least three functions which can be carried out by the small ribosome subunit in the absence of the large subunit: (a) binding of mRNA, (b) formation of the complex aminoacyl-tRNA-small subunit-mRNA and (c) formation of the complex f-Met-tRNA-30S-AUG or natural mRNA. There are also a number of functions specifically catalyzed by the larger ribosome subunit: (a) peptide bond formation, (b) EF-T-dependent (in prokaryotic systems) and EF-1-dependent (in eukaryotic systems) GTP hydrolysis which normally takes place coupled to aminoacyl-tRNA binding to the ribosome and (c) EF-G-dependent (in prokaryotic systems) and EF-2-dependent (in eukaryotic systems) which normally takes place coupled to the complex step of translocation. 


\section{PROTEIN SYNTHESIS INHIBITORS}

Table 2. Inhibitors of protein synthesis acting on prokaryotic ribosomes

\begin{tabular}{|c|c|}
\hline \multicolumn{2}{|c|}{ Small subunit of action } \\
\hline Aurintricarboxylic acid & Streptomycin group: \\
\hline Edcine $A_{1}$ & Gentamycin \\
\hline Kasugamycin & Hygromycin B \\
\hline Pactamycin & Kanamycin \\
\hline Poly(dextran sulphate) & Neomycin \\
\hline Poly(vinyl sulphate) & Paromomycin \\
\hline Spectinomycin & Streptomycin \\
\hline & Tetracycline group: \\
\hline & Chlortetracycline \\
\hline & Doxycycline \\
\hline & Oxytetracycline \\
\hline & Tetracycline \\
\hline \multicolumn{2}{|c|}{ Larger subunit of action } \\
\hline Actinobolin & Macrolides group: \\
\hline Althiomycin & Angolamycin \\
\hline Amicetin & Carbomycin \\
\hline Blasticidin $\mathrm{S}$ & Erythromycin \\
\hline Bottromycin $\mathrm{A}_{2}$ & Forocidin \\
\hline Chloramphenicol group & Lancamycin \\
\hline Chloramphenicol & Leucomycin \\
\hline D-AMP-3 & Methymycin \\
\hline D-Thiomycetin & Neospiramycin \\
\hline D-Win -5094 & Oleandomycin \\
\hline & Spiramycin \\
\hline & Tylosin \\
\hline Fusidic acid & Puromycin \\
\hline Gougerotin & Siomycin group: \\
\hline Lincomycin group: & Siomycin \\
\hline Celesticetin & Sporangiomycin \\
\hline Clindamycin & Thiopeptin \\
\hline Lincomycin & Thiostrepton \\
\hline & Sparsomycin \\
\hline & Streptogramin A group: \\
\hline & Ostreogrycin $\mathrm{G}$ \\
\hline & Streptogramin A \\
\hline & Streptogramin B group: \\
\hline & Staphylomycin S \\
\hline & $\begin{array}{l}\text { Streptogramin B } \\
\text { Viridogrisein }\end{array}$ \\
\hline
\end{tabular}

By using a number of the experimental approaches indicated above it has been possible to elucidate the ribosome subunit in which some antibiotics act (Tables 2 and 3). Although fusidic acid is known to affect directly EF-G (in prokaryotic systems) and EF-2 (in eukaryotic systems) it is included in Tables 2 and 3 as acting on the larger ribosome subunit since the antibiotic has been shown to bind forming the complex EF-G-or EF-2-larger ribosome subunit-GDP-fusidic acid ${ }^{24,25}$.

\section{INHIBITORS OF THE INITIATION PHASE}

Most of the inhibitors which are known to block the initiation phase of protein synthesis are shown in Table 4. Most of these compounds interact 


\section{VAZQUEZ}

with the smaller ribosome subunit. The antibiotic edeine $A_{1}$ and the compounds aurintricarboxylic acid, poly(dextran sulphate) and poly(vinyl sulphate) by binding to the smaller ribosome subunit of either prokaryotic or eukaryotic ribosomes block codon-anticodon interaction of the initiator

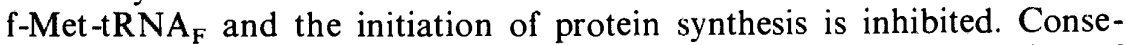
quently the above inhibitors also block codon-anticodon interaction of peptidyl-tRNA of the growing chains at the level of the small subunit which is supposed to take place at the same place as the codon-anticodon interaction of the initiator; because of this, aurintricarboxylic acid, edeine $A_{1}$, poly(dextran sulphate) and poly(vinyl sulphate) are also inhibitors of the elongation phase. Furthermore these inhibitors have been shown to block equally well binding of f-Met-tRNA and aminoacyl-tRNA to the small

Table 3. Inhibitors of protein synthesis acting on eukaryotic ribosomes

\begin{tabular}{lc} 
& Smaller subunit of action \\
Aurintricarboxylic acid & Tetracycline group: \\
Edeine A $_{1}$ & Chlortetracycline \\
Pactamycin & Doxycycline \\
Poly(dextran sulphate) & Oxytetracycline \\
Poly(vinyl sulphate) & Tetracycline \\
Sodium fluoride & \\
& \\
Actinobolin & Larger subunit of action \\
Amicetin & Gougerotin \\
Anisomycin & Puromycin \\
Blasticidin S & Sparsomycin \\
Fusidic acid & Tylophora alkaloids: \\
Glutarimide group: & Cryptopleurine \\
Actiphenol & Tylocrebrine \\
Cycloheximide & Tylophorine \\
Streptimidone & Trichodermin \\
Streptovitacin A & Tenuazonic acid \\
\hline
\end{tabular}

subunit. This might be considered a surprising result since the two-sites translocation model admits binding of donor and acceptor substrates taking place to different sites of the subunit (Figures 1 and 2); consequently data with the above inhibitors are presented by some workers as supporting a different variant of the translocation model with a single site of codonanticodon interaction on the smaller subunit.

The antibiotics streptomycin, dihydrostreptomycin, kanamycin, gentamycin and paromomycin interact with the $30 \mathrm{~S}$ subunit of prokaryotic ribosomes and do not appear to affect any of the steps $2 \mathrm{a}$ and $2 \mathrm{~b}$ but destabilize the entire initiation complex formed in step $2 \mathrm{c}$ when the $50 \mathrm{~S}$ subunit joins the f-Met-tRNA-mRNA-30S complex. This is probably a consequence of some distortion in the P-site since these antibiotics are also inhibitors of the elongation cycle by causing polysome breakdown. 
PROTEIN SYNTHESIS INHIBITORS

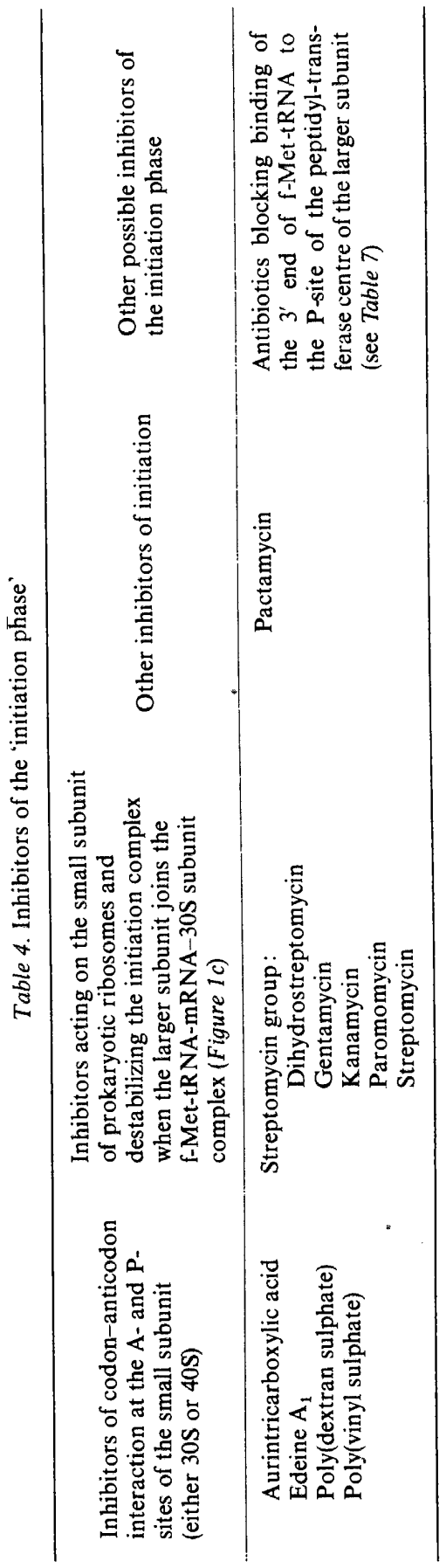


The main effect of the antibiotic pactamycin is located in the smaller subunit of either $70 \mathrm{~S}$ or $80 \mathrm{~S}$ ribosomes. By interacting with the small subunit pactamycin blocks formation of the complex f-Met-tRNA-30S-mRNA in bacterial systems and probably the equivalent reaction taking place in $80 \mathrm{~S}$ type ribosomes.

A number of antibiotics have been shown to block peptide bond formation by interacting with the peptidyl transferase centre of the larger ribosome subunit. Some of these antibiotics have been shown in cell-free systems to block interaction of the CCA-Met-f-or CACCA-Leu-Ac-with the donor-site of the peptidyl transferase centre (Table 7). These inhibitors might be expected to block correct initiation of protein synthesis; in fact this mode of action has already been reported for some of these antibiotics.

\section{INHIBITORS OF THE ELONGATION CYCLE}

\section{Inhibitors of aminoacyl-tRNA binding}

The best known inhibitors of aminoacyl-tRNA binding to the ribosome are shown in Table 5. Included in this Table are edeine $\mathrm{A}_{1}$, aurintricarboxylic acid, poly(dextran sulphate) and poly(vinyl sulphate) which, as indicated above, block interaction codon-anticodon to both A- and P-sites of the smaller subunit. On the other hand the tetracycline group of antibiotics specifically block codon-anticodon interaction at the A-site of the smaller subunit.

A number of antibiotics included in the siomycin group have been shown to block aminoacyl-tRNA binding to bacterial ribosomes at the level of the $50 S$ subunit. Fusidic acid forms the complex fusidic acid-EF-G (or EF-2)ribosome-GDP which prevents under certain conditions translocation (see Table 8) but also aminoacyl-tRNA binding to the larger ribosomal subunit of either bacterial or eukaryotic ribosomes. It is interesting to quote that fusidic acid has been reported to have no effect on Neurospora mitochondrial systems $^{19}$.

Some of the inhibitors of peptide bond formation have been shown to block binding of the terminal CCA-aminoacyl to the acceptor-site of the peptidyl transferase centre (Table 7) and might be considered not only as inhibitors of peptide bond formation but also as inhibitors of aminoacyltRNA binding at the level of the larger ribosomal subunits.

\section{Inhibitors of peptide bond.formation}

The antibiotic puromycin is a structural analogue of the $3^{\prime}$-aminosyladenosine moiety of aminoacyl-tRNA; therefore puromycin acts on the A-site of the peptidyl transferase centre of prokaryotic and eukaryotic ribosomes forming a peptide bond with the initiator amino acid and blocking the correct peptide bond formation. Antibiotics of the chloramphenicol, streptogramin A, lincomycin and some macrolide antibiotics having the mycaminose-mycarose moiety have been shown to block peptide bond formation in most of the experimental systems from bacteria which have been devised (Table 6) although recent results in polysomal systems suggest that some of these antibiotics might not be proper inhibitors of peptide bond formation in intact bacteria ${ }^{10}$. 


\section{PROTEIN SYNTHESIS INHIBITORS}

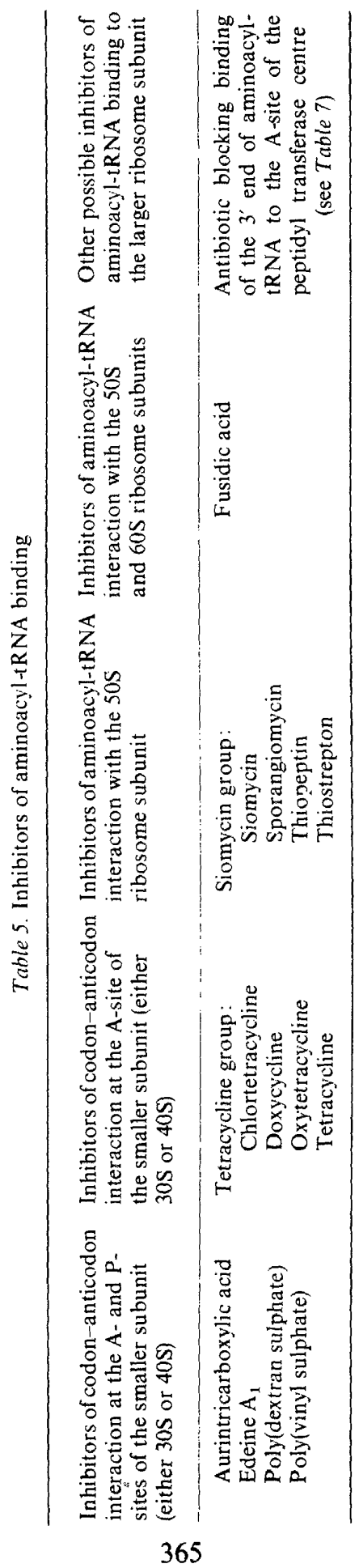


D. VAZQUEZ

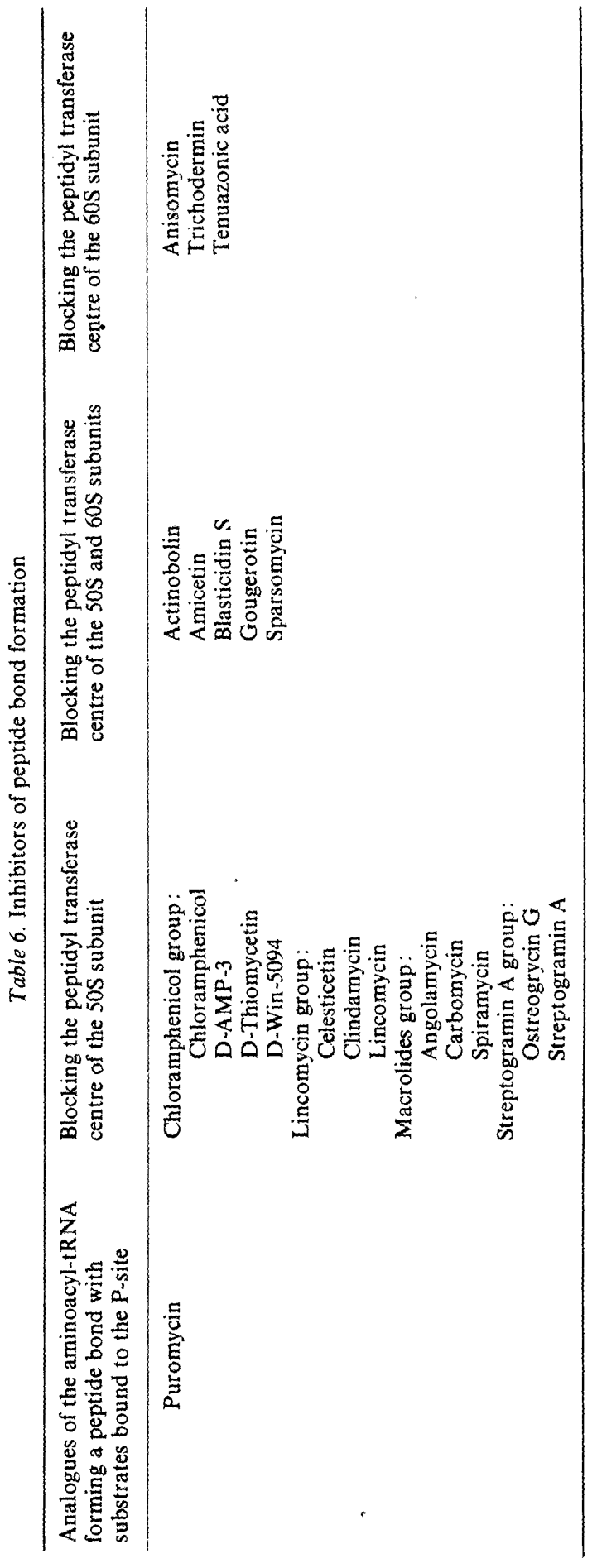


The antibiotics actinobolin, amicetin, blasticidin $\mathrm{S}$, gougerotin and sparsomycin have been found to block peptide bond formation in prokaryotic and eukaryotic systems. However actinobolin is active in some of the systems and the activity of amicetin is very small in some of the ribosomes of the eukaryotic type tested. The antibiotic anisomycin is a very efficient inhibitor of peptide bond formation by ribosomes of the eukaryotic type.

For the reaction of peptide bond formation (Figure $2 e_{1}$ ) the correct binding of the $3^{\prime}$ end of the substrates to the donor-and acceptor-sites of the peptidyl transferase centre is required. Studies on substrate binding have shown that some of the inhibitors of peptide bond formation block binding of the substrate to the acceptor-site of the peptidyl transferase centre whereas some others inhibit substrate binding to both donor-and acceptor-sites (Table 7).

Table 7. Inhibitors of substrate binding to the peptidyl transferase centre

\begin{tabular}{|c|c|c|}
\hline & $\begin{array}{l}\text { Inhibitors of CACCA-Leu-Ac } \\
\text { binding to the P-site }\end{array}$ & $\begin{array}{c}\text { Inhibitors of UACCA-Leu } \\
\text { binding to the A-site }\end{array}$ \\
\hline $\begin{array}{l}50 \text { S ribosome } \\
\text { subunits }\end{array}$ & $\begin{array}{l}\text { Lincomycin group: } \\
\text { Clindamycin } \\
\text { Lincomycin } \\
\text { Macrolides group: } \\
\text { Carbomycin } \\
\text { Spiramycin } \\
\text { Streptogramin A group } \\
\text { Ostreogrycin G } \\
\text { Streptogramin A }\end{array}$ & $\begin{array}{l}\text { Chloramphenicol group: } \\
\text { Chloramphenicol } \\
\text { D-AMP-3 } \\
\text { D-thiomycetin } \\
\text { D-Win-5094 } \\
\text { Lincomycin group: } \\
\text { Clindamycin } \\
\text { Lincomycin } \\
\text { Macrolides group: } \\
\text { Carbomycin } \\
\text { Spiramycin } \\
\text { Streptogramin A group: } \\
\text { Ostreogrycin G } \\
\text { Streptogramin A }\end{array}$ \\
\hline $\begin{array}{l}60 S \text { ribosome } \\
\text { subunits }\end{array}$ & Anisomycin & Anisomycin \\
\hline
\end{tabular}

\section{Inhibitors of translocation}

The step of translocation is one of the most complex and controversial in protein synthesis. Most of the systems used to study translocation are based on the extent of the puromycin reaction before and after treatment with elongation factor-G or -2 which is required for the GTP hydrolysis necessary for translocation. For this reason inhibitors of G-dependent GTP hydrolysis are usually considered as inhibitors of translocation.

Antibiotics of the siomycin group bind to the 50S subunit of bacterial ribosomes and block EF-G dependent GTP hydrolysis and the coupled translocation (Table 8). It is not well known where the site of EF-G interaction with the $50 \mathrm{~S}$ ribosome subunit is located; however, since antibiotics of the siomycin group have also been shown to block aminoacyl-tRNA 
binding to the 50S subunit (Table 5) the results suggest that the binding site for EF-G is overlapping the A-site of the $50 \mathrm{~S}$ subunit.

Resistance to fusidic acid in bacteria is due to alterations in elongation factor-G, locating in this factor the action of the antibiotic. However it has been shown that fusidic acid is active in bacterial as well as eukaryotic systems allowing a single round of GTP hydrolysis and forming initially a stable complex fusidic acid-EF-G (or EF-2)-ribosome-GDP which prevents translocation and subsequent hydrolysis of GTP.

Table 8. Inhibitors of translocation

\begin{tabular}{|c|c|c|}
\hline $\begin{array}{l}\text { Acting on prokaryotic } \\
\text { systems }\end{array}$ & $\begin{array}{l}\text { Acting on prokaryotic } \\
\text { and eukaryotic systems }\end{array}$ & $\begin{array}{c}\text { Acting on eukaryotic } \\
\text { systems }\end{array}$ \\
\hline $\begin{array}{l}\text { Siomycin group: } \\
\text { Siomycin } \\
\text { Sporangiomycin } \\
\text { Thiopeptin } \\
\text { Thiostrepton }\end{array}$ & Fusidic acid & $\begin{array}{l}\text { Diphtheria toxin } \\
\text { Pcderine }\end{array}$ \\
\hline
\end{tabular}

Diphtheria toxin and pederine (a toxin from the insect Paederus fuscipes) have been shown to block translocation only by eukaryotic systems. However these toxins differ in their mode of action. Diphtheria toxin acts enzymatically in the presence of NAD and, by causing ADP-ribosylation of EF-2, blocks translocation. Pederine acts specifically on the ribosome but not on the elongation factors; by binding to ribosomes of eukaryotic cells pederine blocks the translocation and possibly some other steps in protein synthesis. Ribosomes of the insect producer of pederine are resistant to the toxin $^{26}$.

\section{Other inhibitors of the elongation cycle.}

All the inhibitors included in Tables 5-8 obviously block the elongation cycle by preventing some of their partial reactions (aminoacyl-tRNA binding, peptide bond formation and translocation). However some other inhibitors of the elongation cycle have to be considered. Besides inhibiting the initiation phase and probably as a consequence of the same interaction with the ribosome the streptomycin group of aminoglycoside antibiotics are known to block in bacterial systems polypeptide elongation by causing polysome breakdown (Table 9).

There is evidence that a number of antibiotics are inhibitors of the elongation cycle but there is no clear indication of the specific reaction inhibited by some of them. By exclusion of other steps of protein synthesis most of these compounds are usually considered as inhibitors of translocation but certainly there is no clear positive indication in favour of this hypothesis. Among these inhibitors we can include a number of macrolides and antibiotics of the streptogramin B group (Table 9). 


\section{PROTEIN SYNTHESIS INHIBITORS}

Table 9. Inhibitors of the elongation cycle other than those shown in Tables 6 $\backsim 8$

\begin{tabular}{cc}
$\begin{array}{c}\text { Inhibitors causing breakdown of } \\
\text { bacterial polysomes }\end{array}$ & $\begin{array}{c}\text { Other inhibitors of the elongation } \\
\text { cycle }\end{array}$ \\
\hline Streptomycin group: & Macrolide group: \\
Dihydrostreptomycin & Chalcomycin \\
Gentamycin & Erythromycin \\
Kanamycin & Forocidin III \\
Paramomycin & Lancamycin \\
Streptomycin & Methymycin \\
& Neospiramycin III \\
& Oleandomycin \\
& Streptogramin B group: \\
& Staphylomycin S \\
& Streptogramin B \\
& Viridogrisein \\
\hline
\end{tabular}

\section{Inhibitors of the termination phase}

Peptide chain termination is a complex reaction requiring (a) recognition of the nonsense terminating codon, (b) peptidyl-tRNA hydrolysis which is catalyzed by the peptidyl transferase centre and (c) the release reaction specifically catalyzed by the release factors $R_{1}, R_{2}$ and $S$ in bacteria and by the release factor $R$ in mammalian systems. We do not know of any specific inhibitor of this step (c). Recognition of the termination codon UAG has been shown in bacterial systems to be inhibited by streptomycin and tetracycline (Table 10); as tetracycline also binds to $80 \mathrm{~S}$ type ribosomes it is likely that this antibiotic also inhibits termination in eukaryotic systems.

Table 10. Intibitors of the termination phase

\begin{tabular}{cc}
$\begin{array}{c}\text { Inhibitors of interaction of the } \\
\text { nonsense terminating codon }\end{array}$ & Inhibitors of the release reaction \\
$\begin{array}{c}\text { Streptomycin group } \\
\text { Tetracycline group }\end{array}$ & $\begin{array}{c}\text { Inhibitors of peptide bond } \\
\text { formation. (Sec Table 6) }\end{array}$ \\
\hline
\end{tabular}

Peptidyl-tRNA hydrolysis required for peptide chain termination is known to involve the peptidyl esterase centre of the larger ribosome subunit in a reaction very similar in requirements and optimal conditions to that of peptide bond formation. It has been shown indeed that all peptide bond formation inhibitors tested (Table 6) are also inhibitors of the peptidyltRNA hydrolysis required for the termination reaction (Table 10); the specificities of the inhibition are similar as in the case of inhibition of peptide bond formation (Table 6). 


\section{REFERENCES}

1 J. Lucas-Lenard and F. Lipmann, Ann. Rev. Microbiol. 40, 409 (1971).

D. Vazquez and R. E. Monro, Biochim. Biophys. Acta 142, 155 (1967).

${ }^{3}$ D. Vazquez and R. E. Monro, Abhandl. Deut. Akad. Wiss. Berlin, Kl. Medizin, Nr. 1, 569 (1968).

4 D. Vazquez and R. E. Monro, Agrochimica 12, 489 (1968).

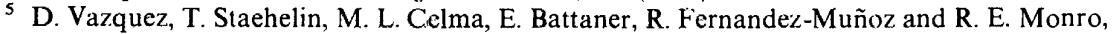
in Inhibitors, tools in cell research, p. 100 (Ed. Th. Bücher and H. Sies), Springer-Verlag. Berlin--Heidelberg-New York (1969).

6 D. Vazquez, T. Staehelin, M. L. Celma, E. Battaner, R. Fernandez-Muñoz and R. E. Monro, FEBS Symposium 21, 109 (1970).

B. Weisblum and J. Davies, Bact. Rev. 32, 493 (1969).

S. Pestka, Ann. Rev. Microbiol, 25, 487 (1971).

9 R. E. Monro, R. Fernandez-Muñoz, M. L. Celma and D. Vazquez, in Drug action and drug resistance in bacteria, p. 303 (Ed. S. Mitsuhashi). (1971) University of Tokyo Press (1971).

10 Various contributions in Molecular mechanisms of antibiotic action on protein biosynthesis and membranes (Ed. E. Muñoz, F. Garcia-Ferrandiz and D. Vazquez). Elsevier Publishing Co., Amsterdam (1972).

11 R. J. Collier and J. A. Traugh, Cold Spring Harb. Symp. Quant. Biol. 34, 589 (1969).

12 D. M. Gill, A. M. Pappenheimer and J. B. Baseman, Cold Spring Harb. Symp. Quant. Biol. 34, 595 (1969).

13 T. Honjo, Y. Nishizuka and O. Hayaishi, Cold Spring Harb. Symp. Quant. Biol. 34, 603 (1969).

14 R. S. Goor and E. S. Maxwell, Cold Spring Harh. Symp. Quant. Biol. 34, 609 (1969).

15 N. Goto, I. Kato and H. Sato, Japan. J. Exp. Med. 38, 185 (1968).

16 A. Tsugawa, Y. Ohsumi and I. Kato, J. Bact. 104, 152 (1970).

17 I. Kato and A. Wattanuki, J. South African Chem. Inst. 22. 125 (1969).

18 M. Grandi and H. Küntzel, FEBS Letters 10, 25 (1970).

${ }_{19}$ M. Grandi, A. Helms and H. Küntzel, Biochem. Biophys. Res. Commun. 44, 864 (1971).

20 F. C. Firkin and A. W. Linnane, FE BS Letters 2, 330 (1969).

21 P. J. Davey, J. M. Haslam and A. W. Linnane, Arch. Biochem. Biophys. 136, 54 (1970).

22 J. M. Haslam, P. J. Davey, A. W. Linnane and M. R. Atkinson, Biochem. Biophys. Res. Commun. 33, 368 (1968).

23. G. Ramirez, I. B. Levitan and E. Mushynski, FE BS Letters 21, 17 (1972).

24 J. W. Bodley and L. Lin, Nature 227, (1970).

25 J. W. Bodley, L. Lin, M. L. Salas and M. Tao, FEBS Letters 11, 153 (1970).

26 O. Tiboni, B. Parisi and O. Ciferri, Giorn. Botanico Ital. 102, 337 (1968). 